\title{
O PROJETO PEDAGÓGICO DA SOCIEDADE DE GEOGRAFIA DO RIO DE JANEIRO: O CURSO SUPERIOR LIVRE DE GEOGRAFIA (1926-1927)1
}

\author{
Luciene Pereira Carris Cardoso \\ Universidade do Estado do Rio de Janeiro \\ lucienecarris@hotmail.com
}

\section{RESUMO:}

Este artigo analisa a trajetória do Curso Superior Livre de Geografia desenvolvido entre os anos de 1926 e 1927 no âmbito da Sociedade de Geografia do Rio de Janeiro, destinado à atualização de professores primários. Organizado por um corpo de especialistas de escol, o projeto pedagógico elaborado por Everardo Backheuser e Delgado de Carvalho, constituiu um experimento de vanguarda, pois pretendia fornecer uma concepção moderna da disciplina.

Palavras-chave: Ensino de Geografia; Sociedade de Geografia do Rio de Janeiro; Intelectuais brasileiros.

\section{THE PEDAGOGICAL PROJECT OF THE GEOGRAPHICAL SOCIETY OF RIO DE JANEIRO: THE SUPERIOR FREE COURSE OF GEOGRAPHY (1926-1927)}

\begin{abstract}
:
This article analyses the history of the Superior Course of Geography between 1926 and 1927 under the perspective of the Rio de Janeiro Geographical Society. Targeting primary school teachers, the course's pedagogical project was structured by high-class specialists like Everardo Backheuser and Delgado de Carvalho and was acknowledged as a vanguard experiment due its modern conception of the discipline.

Key-words: Learning of Geography; Rio de Janeiro Geographical Society; Brazilian intellectuals.
\end{abstract}

\section{INTRODUÇÃO}

Criada em 1883, no contexto do movimento que estimulou a multiplicação de instituições congêneres na Europa e no continente americano, a Sociedade de Geografia do Rio de Janeiro (SGRJ) foi um dos redutos científicos que desfrutou do patrocínio de d. Pedro II. Nos seus primeiros anos, empreendeu um programa de trabalho que buscava responder às demandas do Estado monárquico, por meio de práticas científicas, direcionadas para o melhor conhecimento do espaço físico do Império e de seus habitantes.

Apesar da queda da monarquia, em 1889, e das atribulações que sofreu com a instauração do regime republicano, a Sociedade permaneceu desenvolvendo atividades que pudessem auxiliar no aperfeiçoamento da sociedade, consoante o ideário positivista. Isto se observa nos temas e problemas abordados nas suas sessões, nos estudos e relatos de experiências, nas homenagens e nas conferências proferidas por sócios e ilustres visitantes estrangeiros, a exemplo, do geógrafo francês Elisée Réclus. Preocupação semelhante se nota na seleção de textos para publicação na Revista e nos trabalhos de campo, efetuados por expedições promovidas pela entidade, as quais desbravaram regiões inexploradas do 
país. Tal como correu com a excursão que devassou o norte do estado do Mato Grosso, realizada por Oscar de Oliveira Miranda, José Carlos da Silva Telles, Augusto Ximeno de Villeroy e Antonio Lourenço da Silva Telles Pires, na qual este último perdeu a vida e foi homenageado passando a dar nome a um rio na bacia amazônica. ${ }^{2}$

Esse pragmatismo ganhou um reforço, impulsionado pelo "patriotismo à moda 1914". A exaltação dos recursos naturais, das belezas do solo brasileiro, ao lado da atenção permanente para com a integridade do território nacional e a fixação de suas fronteiras, insuflava os sentimentos cívicos dos membros da instituição. Neste sentido, a Sociedade de Geografia realizou uma série de empreendimentos que alcançaram ampla repercussão no cenário científico e político. Envolveu-se, ainda, nas comemorações do centenário da independência, em 1922. A passagem do Centenário da Independência provocaria grande mobilização nas esferas letradas do Rio de Janeiro. Examinar os cem anos do Estado brasileiro, em primeiro lugar, implicava em romper com padrões estrangeiros e privilegiar idéias essencialmente nacionais. Acrescente-se a isso, a turbulência política que o país atravessava, fruto dos problemas gerados pela crise do pacto político das oligarquias e da descrença dos valores da Belle Époque. Esses elementos impulsionaram o surgimento de uma análise crítica que sublinhava a afinidade entre território e Nação, na qual a geografia passou a desempenhar uma das principais ferramentas de reflexão sobre a nacionalidade. ${ }^{3}$

$\mathrm{Na}$ esteira desse movimento, a Sociedade de Geografia idealizou um projeto de natureza enciclopédica, intitulado de Geografia do Centenário, planejado para alcançar dez volumes. Dirigida ao grande público, a coleção de pretendia, didaticamente, descortinar o Brasil aos brasileiros. Seguiram-se outros projetos de cunho pedagógico, como o Curso Superior Livre de Geografia, que funcionou entre os anos de 1926 e 1927, destinado à atualização de professores primários, organizado por um corpo de especialistas de escol, que reuniu nomes como Fernando Raja Gabaglia, Everardo Backheuser e Delgado de Carvalho.

\section{A IDEALIZAÇÃO DO PROJETO PEDAGÓGICO DA SOCIEDADE DE GEOGRAFIA DO RIO DE JANEIRO}

O empreendimento educacional de cariz nacionalista da SGRJ funcionou gratuitamente nos anos de 1926 e de 1927. É importante ressaltar que iniciativa semelhante fora tomada pelo Instituto Histórico e Geográfico Brasileiro entre os anos 1916 e 1921, com o estabelecimento da "Academia de Altos Estudos", depois transformada em Faculdade de Filosofia e Letras do Instituto Histórico e Geográfico Brasileiro, a qual não conseguiu obter o reconhecimento formal dos poderes públicos. ${ }^{4} \mathrm{O}$ projeto da Sociedade, portanto, convergia com a experiência do Instituto Histórico, na esteira da idéia de que através da educação, seria possível alterar o país. ${ }^{5}$

Aliás, entre as diversas personalidades que participaram do projeto pedagógico do Instituto e que pertenciam aos quadros da Sociedade de Geografia do Rio de Janeiro, destacavam-se Carlos Delgado de Carvalho, Basílio de Magalhães e José Maria Moreira Guimarães. ${ }^{6}$

Para evitar os mesmos transtornos que levaram a experiência do Instituto Histórico ao insucesso, concebeu-se uma proposta menos ambiciosa e destinada apenas à atualização dos professores do ensino primário. Todavia, no artigo XII da "Lei Orgânica do Curso Superior Livre", lê-se que a Sociedade se comprometia a [...] esforçar-se diante das autoridades federais, estaduais e municipais a fim de que seja concedidas certas prerrogativas especiais ou regalias constitucionais não só aos professores, mas aos Laureados em 
Geografia e Ciências Correlatas. ${ }^{7}$ Elaborado pelos sócios Carlos Delgado de Carvalho e Everardo Backheuser, o projeto do Curso pretendia inserir uma nova concepção de geografia na Sociedade, combinando as idéias de Friedrich Ratzel (1844-1904), ${ }^{8}$ com as de Vidal de La Blache (1845-1918). ${ }^{9}$

Carlos Miguel Delgado de Carvalho (1884-1980), nascido na França, formou-se na Escola de Ciências Diplomáticas de Paris e na Escola de Economia e Política de Londres. Transferiu-se para o Brasil em 1906, e a partir daí começou a colaborar na imprensa, redigindo artigos para o Jornal do Comércio. Envolveu-se com o movimento de renovação pedagógica, liderado por Anísio Teixeira. Exerceu o magistério no Colégio Pedro II, onde ministrou cursos de Geografia, de Inglês e de Sociologia. Na Universidade do Distrito Federal, foi professor catedrático dos cursos de Geografia Humana e de História Moderna e Contemporânea. Ocupou, ainda, vários cargos públicos no Conselho Nacional de Educação e no Instituto Nacional de Pesquisas Educacionais. Autor de obras de grande repercussão, a exemplo dos livros Le Brésil Meridional: étude économique sur les états du sud (1910) e Geografia do Brasil (1913), o primeiro considerado hoje em dia um clássico, ${ }^{10}$ e o segundo prefaciado por Oliveira Lima, mas que não obteve uma aceitação imediata, pois [...] o meio cientifico não estava preparado para a fermentação do pensamento geográfico europeu já naquela ocasião bastante avançado. ${ }^{11}$ No fundo, as concepções de vanguarda desenvolvidas por Delgado de Carvalho só seriam assimiladas na década de 1930.

Por sua vez, Everardo Adolpho Backheuser (1879-1951) formou-se em engenharia na Escola Politécnica do Rio de Janeiro, onde mais tarde ingressaria como professor. Colaborou com o jornal $O$ País. Junto com Delgado de Carvalho participou da fundação da Associação Brasileira de Educação. ${ }^{12}$ Associou-se ao grupo que criou a Academia Brasileira de Ciências, fundou a Liga Brasileira de Esperanto e ocupou a vice-presidência da Sociedade de Geografia do Rio de Janeiro. Não por acaso, a partir daí, a Revista da Sociedade de Geografia do Rio de Janeiro passaria a publicar o resumo das matérias editadas em esperanto.

Everardo Backheuser integrou o movimento católico filiando-se à Associação dos Professores Católicos e à Confederação Brasileira de Educação Católica. Foi catedrático da Faculdade de Filosofia da Universidade Santa Úrsula, e ajudou a fundar a Pontifícia Universidade Católica do Rio de Janeiro. Defensor da geografia moderna, fundamentada na escola alemã, em especial, nas concepções formuladas por Friderich Ratzel, publicou $A$ estrutura política do Brasil. Notas Prévias (1929) e Problemas do Brasil: Estrutura geopolítica (1933). Sabe-se que o interesse de Backheuser pela geopolítica datava do período em permaneceu detido na Ilha Rasa, por causa da oposição manifestada ao governo do presidente Arthur Bernardes. Naquela ocasião, José Rodrigues Leite e Oiticica, filólogo e militante anarquista, lhe ofertou a obra Geografia Política (1897) de Ratzel. ${ }^{13}$ Ainda na prisão, Backheuser alinhavou o que seria A estrutura política do Brasil: Notas Prévias (1929), ${ }^{14}$ editado originalmente em fascículos, distribuídos pela imprensa carioca, divulgação que considerava como a forma mais eficaz para atingir o grande público.

Backheuser foi um dos pioneiros na introdução do pensamento geopolítico no Brasil, dedicando-se ao estudo e às possibilidades da sua aplicação às reformas do Estado. ${ }^{15}$ Mais tarde, em 1933, voltou sua atenção para a questão da divisão territorial do Brasil. Aproveitando o momento em que se discutia a nova Carta Constitucional publicou o livro Problemas do Brasil (1933). ${ }^{16}$

Tanto Everardo Backheuser quanto Delgado de Carvalho destacavam a importância da relação entre o homem e o meio natural. Aspiravam implantar e difundir uma geografia moderna no país, a partir do efetivo conhecimento do seu território, e colaboraram no 
estabelecimento de diversas instituições, tais como o Conselho Nacional de Geografia (1933), a Associação dos Geógrafos Brasileiros (1934) e o Instituto Brasileiro de Geografia e Estatística (1938). Porém, enquanto o primeiro como já se mencionou, inspirava-se na antropogeografia ratzeliana, o segundo buscava os seus referenciais teóricos na geografia francesa, sobretudo em Vidal de La blache. Essa diferenciação de abordagem aprofundou-se quando Backheuser vinculou-se ao movimento católico em 1928. ${ }^{17}$

O Curso Superior Livre da Sociedade visava conferir o título de "Laureado em Geografia e Ciências Correlatas" e seria coordenado por uma comissão pedagógica composta por Delgado de Carvalho, Fernando Antonio Raja Gabaglia e Everardo Backheuser, cabendo a este último elaborar o planejamento curricular. O plano de estudos compreendia dois semestres, perfazendo um total de oitenta aulas com duração de cinqüenta minutos. Apesar de gratuito, previa-se o pagamento de uma taxa de matrícula destinada à aquisição de livros e revistas para a formação de uma biblioteca própria. Ao final do curso, os alunos prestavam prova e redigiam uma monografia, sobre um tema específico, com no mínimo cinco laudas. Receberiam o diploma, aqueles que tivessem frequiência igual ou superior a oitenta por cento das aulas. Segundo Delgado de Carvalho, tratava-se de um projeto pedagógico eminentemente pragmático:

[...] Não planejamos um curso especializado de geografia superior, não planejamos tão pouco um curso de pedagogia superior, não planejamos mesmo um curso de pedagogia da geografia elementar. Desejamos apenas, nos diferentes ramos escolhidos e que se completam, apresentar um certo número de pontos de vista, de explicações, chamando a atenção do auditório para feições interessantes e de utilidade prática.18

Em 25 de maio de 1926, Everardo Backheuser proferiu a aula inaugural do Curso Superior Livre de Geografia, assistida pelo reitor da Universidade do Rio de Janeiro, o Conde de Afonso Celso e Antônio Carneiro Leão, Diretor Geral da Instrução Pública, além de diversas personalidades do cenário político e intelectual, da administração pública e de profissionais do magistério.

Everardo Backheuser estabeleceu as distinções entre o que denominou da "geografia vestida à moda antiga" e a nova concepção da disciplina, que norteava o Curso. Enquanto a antiga se resumia apenas na descrição da superfície terrestre (a enumeração dos acidentes geográficos), a nova se caracterizava por ser: [...] uma geografia em que se raciocina, que explica; que induz, que deduz, que prevê fatos físicos e acontecimentos sociais; uma geografia que tem, portanto todos as característicos de uma verdadeira ciência [...]. ${ }^{19}$ Para Backheuser, tal concepção se orientava pelos seguintes fundamentos: $1^{\circ}$ as relações de interdependência entre o clima, o solo e o homem, "agindo e reagindo uns sobre os outros"; $2^{\circ}$ o conceito de região, a delimitação do espaço a ser analisado; $3^{\circ}$ a definição de paisagem natural ou cultural, enquanto a primeira transformava-se lentamente, a segunda era volúvel e mudava de maneira acelerada. $^{20}$ Finalmente, procurou redefinir o caráter científico do conhecimento geográfico, sublinhando que ao invés do paradigma comteano de "ciência abstrata", a nova geografia seguia o modelo da zoologia, da botânica e da antropologia. Aproximavase da sociologia, tornando-se "algo de ciência natural e algo de ciência social". ${ }^{21}$

A iniciativa da Sociedade obteve repercussão favorável nos meios letrados. Entre aqueles que se mostravam mais entusiasmados com o empreendimento destacou-se o conde 
Afonso Celso, figura respeitada tanto do ponto de vista intelectual, quanto pelo seu engajamento em campanhas nacionalistas. ${ }^{22}$ Ele escreveu um artigo para o Jornal do Brasil, reproduzido na Revista, intitulado "A nova concepção de geografia", em que enaltece o valor do Curso Superior Livre e justifica a sua contribuição para a formação dos futuros dirigentes do país:

Ao ponto de vista do sentimento patriótico, ninguém contestará a vantagem para a mocidade em instruir-se, mediante o estudo da geografia racional, do que há de realmente superior no Brasil, relativamente às outras nações, bem como do que existe de somenos e seja carecedor de retoque ou adaptação ao progredimento [ sic] nacional. ${ }^{23}$

Para Afonso Celso, era lamentável a falta de estudos superiores de geografia. Sobretudo, porque nos estabelecimentos de ensino de $3^{\circ}$ grau já funcionavam cursos de sociologia e de economia política. Neste sentido, ele postulava a institucionalização da disciplina, ao mesmo tempo em que louvava o projeto recém implantado - mais um dos "valiosos serviços" prestados à nação pela Sociedade, nos seus quarenta anos de existência. ${ }^{24}$ A primeira turma do Curso Superior Livre de Geografia, ingressa em 1926, cumpriu a seguinte grade curricular, em dois períodos letivos:

Tabela n. 1

Grade Curricular do Curso Superior Livre de Geografia

Sociedade de Geografia do Rio de Janeiro

Ano de 1926

\begin{tabular}{|l|l||}
\hline Disciplina: 10 Período & Professor \\
\hline Cosmografia & Delgado de Carvalho \\
\hline Fisiografia e Paleografia & Everardo Backheuser \\
\hline Meteorologia e Climatologia & Delgado de Carvalho \\
\hline Gétodos Estatísticos e Desenho de Cartas & Luis Caetano de Oliveira \\
\hline Ecologia & Edgar Sussekind de Mendonça \\
\hline Disciplina: $\mathbf{2}^{\mathbf{0}}$. Período & Professor \\
\hline Metodologia e História da Geografia & Delgado de Carvalho \\
\hline Etnografia e Antropologia & Heloísa Alberto Torres \\
\hline Geopolítica & Everardo Backheuser \\
\hline Forças Econômicas & Delgado de Carvalho \\
\hline Movimentos da População & Fernando Raja Gabaglia \\
\hline
\end{tabular}

Fonte: Revista da Sociedade, Rio de Janeiro, t. 21, 1926-1927, p. 102-103.

Como se observa, o corpo docente reunir figuras expressivas, recrutadas não apenas entre os membros da Sociedade, mas também em outras instituições, como a Escola Politécnica do Rio de Janeiro, o Colégio Pedro II, a Escola Normal e o Museu Nacional, que [...] representam a vanguarda do grande movimento em favor da geografia que está se delineando. ${ }^{25}$ Embora a maior parte das disciplinas fosse ministrada por Delgado de Carvalho e Everardo Backheuser, há que se notar no corpo docente os nomes de Edgar Sussekind de Mendonça, ${ }^{26}$ de Honório de Sousa Silvestre, ${ }^{27}$ de Luiz Caetano de Oliveira. ${ }^{28}$ 
Sem falar da participação feminina, com a presença de Heloísa Alberto Torres, nome-chave no processo de institucionalização da Antropologia e das Ciências Sociais no Brasil. ${ }^{29}$

Em 1927, coube a Delgado de Carvalho pronunciar a aula magna do Curso. Do mesmo modo que Backheuser, Carvalho, postulava o resgate da geografia como uma ciência natural, erradicando-a de nomes próprios [...] que nada nos explicam, que nada nos contam. Tal "restauração" deveria desaguar em um movimento a favor de uma "escola brasileira de geografia", envolvendo uma gama de intelectuais liderados por Backheuser, ao lado de Raja Gabaglia, Honório Silvestre, Otelo Reis no magistério, e Arrojado Lisboa, Eusébio de Oliveira, Ruy de Lima e Silva, Alberto Betim, Djalma Guimarães, Roquette Pinto, Alberto Rangel, que atuavam no campo da pesquisa.

Afinado com os pressupostos de Vidal de la Blache, Delgado se deteve nos aspectos, que no seu entender, constituíam a nova geografia física e ressaltou a ação da longa duração sobre o meio natural, para apresentar a sua versão do curso de Fisiografia, o qual iria ministrar naquele ano. ${ }^{30}$ Anunciou a revisão do conteúdo programático da disciplina, planejado para se distribuir em dez ou doze palestras, compreendendo os seguintes temas: as feições maiores do relevo; o trabalho erosivo da atmosfera ou deflação; as águas subterrâneas, as fontes e o lençol d'água; as águas correntes; a glaciação; os lagos; a abrasão ou ação erosiva do mar; os fenômenos vulcânicos e o diastrofismo ou movimentos da crosta terrestre. Pretendia, assim, elucidar os "grandes enigmas e segredos da fisiografia terrestre", para os professores do ensino primário das escolas públicas que, por sua vez, seriam os responsáveis pela formação das futuras gerações de cidadãos. ${ }^{31}$

Tabela n. 2

Grade Curricular do Curso Superior Livre de Geografia Sociedade de Geografia do Rio de Janeiro

Ano de 1927

\begin{tabular}{|l|l|}
\hline Disciplina & Professor \\
\hline Fisiografia e Paleografia & Delgado de Carvalho \\
\hline Cosmografia & Honório de Sousa Silvestre \\
\hline Antropogeografia & Everardo Backheuser \\
\hline Estatística & Luis Caetano de Oliveira \\
\hline Climatologia & Jorge Machado \\
\hline Etnografia e Antropologia & Heloísa Alberto Torres \\
\hline Ecologia & Abel Pinto \\
\hline Oceanografia & Roberto Freire Seidl \\
\hline Modelagem geográfica & Delgado de Carvalho \\
\hline Distrito Federal (Excursões) & Everardo Backheuser \\
\hline
\end{tabular}

Fonte: Revista da Sociedade, T. XXI, 1926-1927, p. 102-103.

Em relação ao currículo oferecido em 1926, além da mudança no conteúdo e na abordagem da disciplina Fisiografia, constata-se que cadeira "Métodos Estatísticos e Desenho de Cartas Geográficas" desdobrou-se em duas, "Estatística" e "Modelagem Geográfica"; a de Meteorologia e Climatologia passou a se denominar apenas Climatologia; as matérias Metodologia e História da Geografia, Geopolítica, Forças Econômicas e Movimentos da População foram suprimidas, cedendo lugar à Estatística, à Antropogeografia e à Oceanografia. Acrescentou-se, também uma parte prática ao Curso, 
por assim dizer, com a programação de seis excursões no Distrito Federal, guiadas por Everardo Backheuser, de maneira a articular os estudos teóricos com observações de campo.

A estrutura e o funcionamento do Curso Superior Livre evidenciavam as mais recentes tendências e orientações teóricas do saber geográfico. Além das abordagens inovadoras, do ponto de vista do seu conteúdo, o Curso também se caracterizou pela originalidade, com a introdução do ensino das disciplinas Ecologia e Oceanografia. A primeira, lecionada por Edgar Sussekind de Mendonça, corresponde a um campo do conhecimento que só viria a se consolidar muitos anos mais tarde. Lamentavelmente, porém, na documentação da Sociedade não há vestígios do plano de estudos desenvolvido por Sussekind.

Quanto à oceanografia, apesar da carência das fontes da Sociedade, descobrimos que o programa da disciplina, preparado pelo professor Roberto Freire Seidl, ${ }^{32}$ foi publicado em 1929. O curso dividia-se em seis lições: oceanografia; topografia e litologia do oceano; física e química do mar; movimentos do mar; fauna e flora marítima e mares polares. ${ }^{33} \mathrm{Na}$ lição inaugural, Seidl delineia um panorama histórico dos estudos de oceanografia, um campo do conhecimento ainda em formação. Ele deplora a [...] inópia e o atraso do Brasil nestes assuntos, país possuidor de mais de oito mil quilômetros de costa marítima, ao mesmo tempo em que salienta as "vantagens práticas da exploração racional dos oceanos", apesar de assinalar a extrema dificuldade do seu estudo, devido à falta de instrumentos técnico-científicos. ${ }^{34}$

Ao que tudo indica, o esforço dos coordenadores e o brilhantismo daquele grupo de professores não foi o suficiente para manter o funcionamento do Curso, pois, sabe-se que no segundo de atividades houve uma redução considerável do número de alunos. ${ }^{35}$ Embora na documentação disponível na Sociedade de Geografia do Rio de Janeiro não exista nenhuma relação dos alunos laureados em Geografia e Ciências Correlatas, é viável supor que houve quem concluísse o Curso, uma vez que na Revista informa-se que a entrega dos diplomas poderia ser realizada em sessão solene na Sociedade ou diretamente na secretaria. De qualquer forma, tratava-se de um projeto educacional afinado com as idéias vigentes, ou seja, percebia o estudo da geografia e da história como instrumentos para a disseminação do patriotismo e para exaltação da grandeza nacional, o que confirma as premissas de Ruy Moreira e de José William Vesentini, a respeito do processo de institucionalização do conhecimento geográfico e do seu ensino no Brasil. ${ }^{36}$

\section{REFERÊNCIAS BIBLIOGRÁFICAS}

BACKEHEUSER, Everardo. “A nova concepção da geografia. Conferência realizada pelo professor dr. Everardo Backheuser, inaugurando as preleções do Curso Superior Livre de Geografia". Revista da SGRJ, Rio de Janeiro, t. 31, 1926-1927.

A estrutura política do Brasil. Notas Prévias. Rio de Janeiro: Mendonça, Machado \& Cia. Editores, 1929.

Problemas do Brasil: Estrutura geopolítica. Rio de Janeiro: Omnia, 1933.

BERNARDES, Nilo Bernardes. "A influência estrangeira no desenvolvimento da geografia no Brasil". Rio de Janeiro: Revista Brasileira de Geografia, ano. 44, n.3, jul./set. 1982, p. 521.

CARDOSO, Luciene P. Carris. Sociedade de Geografia do Rio de Janeiro: espelho das tradições progressistas (1910-1945). Tese (Doutorado) - Instituto de Filosofia e Ciências 
Humanas, Programa de Pós-Graduação em História Política, Universidade do Estado do Rio de Janeiro, Rio de Janeiro, 2008.

. Sociedade de Geografia do Rio de Janeiro: Identidade e Espaço Nacional (18831909). Dissertação (Mestrado) - Instituto de Filosofia e Ciências Humanas, Universidade do Estado do Rio de Janeiro, Programa de Pós Graduação em História Política, Rio de Janeiro, 2003.

CARVALHO, Delgado de. "Geografia - Ciência da Natureza". Revista da SGRJ, Rio de Janeiro, t. 31, 1926-1927.

CELSO, Afonso. "A nova concepção de geografia". Revista da SGRJ, Rio de Janeiro, t. 31, 1926-1927.

CORRÊA, Mariza. Antropólogas e antropologia. Belo Horizonte: Editora UFMG, 2003.

CORRÊA. Roberto Lobato Corrêa. Região e organização espacial. São Paulo: Ática, 1991.

FAVERO, Maria de Lourdes de Albuquerque \& BRITTO, Jader de Medeiros. Dicionário de Educadores no Brasil. Rio de Janeiro; UFRJ, MEC-INEP-Comped, 2002.

GOMES, Paulo César da Costa. Geografia e Modernidade. Rio de Janeiro: Bertrand Brasil, 1996.

GUIMARÃES, Lúcia Maria. Paschoal, Da escola palatina ao silogeu: Instituto Histórico e Geográfico Brasileiro (1889-1938), Rio de Janeiro: Museu da República, 2007.

MORAES, Antonio Carlos Robert de. Geografia: pequena história crítica. São Paulo: Hucitec, 1999. . (org.), Ratzel. São Paulo: Ática, 1990.

MOREIRA, Ruy. O Discurso do Avesso (para a crítica da geografia que se ensina). Rio de Janeiro: Dois Pontos, 1987.

MOREIRA, Ruy. O que é geografia. São Paulo: Brasiliense, 1986.

MOTTA, Marly da Silva. “1922: em busca do Brasil moderno”. Rio de Janeiro: CPDOC, 1994.

MYAMOTO, Shiguenoli. Geopolítica e poder no Brasil. São Paulo: Papirus, 1995.

OLIVEIRA, Luiz Caetano de. Rudimentos de cálculo diferencial e de cálculo integral. São Paulo: Melhoramentos, 1939.

RAFFESTIN, Claude. Por uma geografia do poder. São Paulo: Ática, 1993.

SANTOS, Sydney M. G. dos. A cultura opulenta de Everardo Backheuser: os conceitos e as leis básicas de geopolítica. Rio de Janeiro: Carioca Engenharia S. A., 1989.

SEIDL, Roberto Freire. Oceanografia (Formação e desenvolvimento). Rio de Janeiro, Est. Graphico Roland Rohe, 1929.

SGRJ, "Curso superior livre de geografia". Revista da SGRJ, Rio de Janeiro, t. 31, 192627.

SGRJ, "Relatório do Presidente da Sociedade general Moreira Guimarães relativo ao ano social de 1926". Revista da SGRJ, Rio de Janeiro, t.31, 1926-1927. 
SILVESTRE, Honório de Sousa. Notas a fisiografia do Brasil(Separata do Anuário do Colégio Pedro II), Rio de Janeiro, 1922.

VESENTINI, José William. "Controvérsias geográficas: epistemologia e política" Confins, Revue Franco-brésilienne de Geographie, n. 2, 1 semestre, 2008. [En ligne], mis en ligne le 17 février 2008. URL : http://confins.revues.org/document1162.html. Consulté le 17 juillet 2008.

Para uma geografia crítica da escola. São Paulo: Editora do autor, 2008.

ZUZMAN, Perla Brígida. Sociedades Geográficas na promoção do saber a respeito do território: Estratégias políticas e acadêmicas das instituições geográficas na Argentina (1782-1942) e no Brasil (1838-1945). (Dissertação) Mestrado - Faculdade de Filosofia, Letras e Ciências Humanas, Programa de Pós-Graduação em Geografia, Universidade de São Paulo, São Paulo,1996.

Notas:

${ }^{1} \mathrm{O}$ presente artigo constitui uma parte do capítulo da tese de doutorado Sociedade de Geografia do Rio de Janeiro: espelho das tradições progressistas (1910-1945), defendida em dezembro de 2008 no Programa de Pós-Graduação em História Política, Instituto de Filosofia e Ciências Humanas, Programa de Pós-Graduação em História Política, Universidade do Estado do Rio de Janeiro. A pesquisa recebeu apoio da Fundação de Amparo à Pesquisa do Rio de Janeiro (Faperj).

2 Cf. CARDOSO, Luciene P. Carris, Sociedade de Geografia do Rio de Janeiro: Identidade e Espaço Nacional (1883-1909). Dissertação (Mestrado), Instituto de Filosofia e Ciências Humanas, Programa de Pós Graduação em História Política, Universidade do Estado do Rio de Janeiro, 2003.

${ }^{3}$ Marly da Silva Motta, “1922: em busca do Brasil moderno”. Rio de Janeiro: CPDOC, 1994, p. 06.

${ }^{4}$ Cf. Lúcia M. Paschoal Guimarães, Da escola palatina ao silogeu: Instituto Histórico e Geográfico Brasileiro (1889-1938), Rio de Janeiro: Museu da República, 2007.

${ }^{5}$ Idem, p. 106.

${ }^{6} \mathrm{O}$ projeto da Sociedade de Geografia inseria-se no contexto das propostas de reformas pedagógicas, que culminaram com o surgimento da Associação Brasileira de Educação, em 1924. Tais propostas se caracterizavam pela defesa da escola pública, universal e gratuita, segundo o modelo da Escola Nova ou Progressista do pedagogo americano John Dewey. Cf. "Curso superior livre de geografia". Revista da SGRJ, Rio de Janeiro, t. 31, 1926-27, p. 239.

${ }^{7}$ SGRJ, “Curso Superior Livre de Geografia”, Revista da SGRJ, Rio de Janeiro, t. 31, 1926-1927, p. 71-74.

${ }^{8}$ Friedrich Ratzel (1844-1904) foi o principal expoente da escola geográfica alemã do final do século XIX. Em 1882, publicou o livro Antropogeografia: fundamentos da aplicação da geografia à história que revela a influência do meio físico sobre o homem. Nos anos seguintes, editou As raças humanas (1885-1888) em três volumes, O Estado e o seu solo estudados geograficamente (1896) e Geografia Política (1897). Da análise interdisciplinar, Ratzel articula o conhecimento histórico, os estudos etnológicos e a geografia para apreender a dinâmica da dispersão dos povos na superfície terrestre, a formação do território físico, bem como as distribuições dos povos e as raças. Outros temas como as fronteiras, o estado, as relações internacionais, as guerras também foram objeto de seu exame. Cf. Antonio Carlos Robert de Moraes, Geografia: pequena história crítica. São Paulo: Hucitec, 1999. Shiguenoli Myamoto, Geopolítica e poder no Brasil. São Paulo: Papirus, 1995; Ruy Moreira, O que é geografia. São Paulo: Brasiliense, 1986; Antonio Carlos Robert de Moraes (org.), Ratzel. São Paulo: Ática, 1990.

${ }^{9}$ Paul Vidal de La Blache (1845-1918) privilegiou os estudos de Geografia Política. Impulsionado pelo contexto político e social francês, transferiu a importância que Ratzel conferia ao Estado para a sociedade. A perda da região francesa da Alsácia-Lorena para a Prússia, durante a guerra franco-prussiana promoveu um amplo debate no cenário intelectual e político francês o que culminou no argumento de que a perda territorial 
foi causada pelo desconhecimento geográfico, e não pelo poderio do exército alemão. Para o sábio francês, o objeto da geografia era a relação do homem e da natureza, segundo Antônio Carlos Robert Moraes, [...] $L a$ Blache colocou o homem como um ser ativo, que sofre a influência do meio, porém que atua sobre este, transformando-o. Ver: Antonio Carlos Robert de Moraes, Geografia: pequena história crítica. São Paulo: Hucitec, 1999; Paulo César da Costa Gomes, Geografia e Modernidade. Rio de Janeiro: Bertrand Brasil, 1996; Roberto Lobato Corrêa, "As correntes do pensamento geográfico". In: espacial. São Paulo: Ática, 1991. Região e organização

${ }^{10}$ Nas primeiras décadas do século XX, Delgado de Carvalho também publicou as seguintes obras: Um centre économique au Brésil: l'êtat de Minas (1908), Geografia do Brasil (1913), Métèorologie du Brésil (1917), Physiografia do Brasil (1922), Metodologia do Ensino de Geografia: introdução aos estudos da geografia moderna (1925) e Introdução a Geografia Política (1929).

${ }^{11}$ Nilo Bernardes, "A influência estrangeira no desenvolvimento da geografia no Brasil". Rio de Janeiro: Revista Brasileira de Geografia, ano. 44, n.3, jul./set. 1982, p. 521.

12 No âmbito dos estudos pedagógicos, ver, Everardo Backheuser, Técnica da Pedagogia Moderna: teoria e prática da Escola Nova (1934), Técnica da pedagogia moderna: teoria e prática da Escola Naval (1934) e O trabalho das escolas experimentais no Distrito Federal (1937).

${ }^{13}$ Com a publicação de Geografia Política em 1897, Ratzel explicitou as relações entre o solo e o homem e o crescimento espacial dos estados ao longo da história, mostrando-se precursor da geopolítica. Esta corrente dedicou-se ao estudo da dominação dos territórios, referentes à ação do Estado sobre o espaço territorial. Da escola alemã ratzeliana surgiu a concepção do "determinismo geográfico", criada por militares e políticos europeus que defendiam a exploração das colônias. Além de teorias como a que responsabilizava o clima pela "indolência do homem tropical" e pelo "subdesenvolvimento dos países tropicais". Alguns autores discorreram sobre as formas de operacionalizar e legitimar o imperialismo, tais como: Rudolf Kjéllen (18641922), Harford Mackinder (1861-1947), Alfred Thayer Mahan (1840-1814) e Karl Haushofer (1862-1945). Cf. Antonio Carlos Robert de Moraes, op. cit.; Shiguenoli Myamoto, op. cit.; Claude Raffestin, Por uma geografia do poder. São Paulo: Ática, 1993.

${ }^{14}$ Everardo Backheuser, A estrutura política do Brasil. Notas Prévias. Rio de Janeiro: Mendonça, Machado \& Cia. Editores, 1929.

${ }^{15}$ Sydney M. G. dos Santos, A cultura opulenta de Everardo Backheuser: os conceitos e as leis básicas de geopolítica. Rio de Janeiro: Carioca Engenharia S. A., 1989, p. 199.

${ }^{16}$ Everardo Backheuser, Problemas do Brasil: Estrutura geopolítica. Rio de Janeiro: Omnia, 1933, p.73.

${ }^{17}$ Sobre esse assunto ver: Perla Brígida Zuzman, Sociedades Geográficas na promoção do saber a respeito do território: Estratégias políticas e acadêmicas das instituições geográficas na Argentina (1782-1942) e no Brasil (1838-1945). (Dissertação) Mestrado - Faculdade de Filosofia, Letras e Ciências Humanas, Universidade de São Paulo, São Paulo,1996, p. 140.

${ }^{18}$ Delgado de Carvalho, "Geografia - Ciência da Natureza". Revista da SGRJ, Rio de Janeiro, t. 31, 19261927, p. 96.

${ }^{19}$ Everardo Backheuser, "A nova concepção da geografia. Conferência realizada pelo professor dr. Everardo Backheuser, inaugurando as preleções do Curso Superior Livre de Geografia". Revista da SGRJ, Rio de Janeiro, t. 31, 1926-1927, p. 78.

${ }^{20}$ O geógrafo alemão Otto Maull (1887 -1957) se destacou em estudos de geopolítica, geomorfologia e geografia física do Brasil. Cf. José Veríssimo da Costa Pereira, "A geografia no Brasil". In: Fernando de Azevedo, As ciências no Brasil. Rio de Janeiro: UFRJ, 1994, p. 436.

${ }^{21}$ Evarardo Backheuser, op. cit., p. 80.

${ }^{22}$ Como já se informou, Afonso Celso era sócio efetivo da SGRJ, membro da Academia Brasileira de Letras e presidente do Instituto Histórico e Geográfico Brasileiro.

${ }^{23}$ Afonso Celso, “A nova concepção de geografia”. Revista da SGRJ, Rio de Janeiro, t. 31, 1926-1927, p. 9093.

${ }^{24}$ Idem. 
${ }^{25}$ Delgado de Carvalho, "Geografia - Ciência da Natureza". Revista da SGRJ, Rio de Janeiro, t. 31, 19261927, p. 94.

${ }^{26}$ Edgar Sussekind de Mendonça formou-se na Escola Nacional de Belas Artes, envolveu-se também com o movimento de reforma do ensino, ao lado de Delgado de Carvalho e Raja Gabaglia, e da Reforma da Instrução Pública liderada por Fernando de Azevedo da década de 1930. Ministrou as disciplinas de ciências físicas e naturais da Escola Normal. Escreveu diversos compêndios e programas de ciências físicas e naturais, geografia e história natural aplicada. Cf. Maria de Lourdes de Albuquerque Favero \& Jader de Medeiros Britto, Dicionário de Educadores no Brasil. Rio de Janeiro; UFRJ, MEC-INEP-Comped, 2002, p.285-290.

${ }^{27}$ Honório de Sousa Silvestre,professor catedrático do Colégio Pedro II redigiu a obra Notas a fisiografia do Brasil (1922), que no seu entender, reunia [...] cousas esparsas sobre a geografia física do Brasil. Cf. Honório de Sousa Silvestre, Notas a fisiografia do Brasil(Separata do Anuário do Colégio Pedro II), Rio de Janeiro, 1922.

${ }^{28}$ Luiz Caetano de Oliveira, engenheiro e professor da Escola Politécnica do Rio de Janeiro e do Colégio Santo Inácio, colaborou na Comissão de Melhoramentos e Obras Municipais (1914), além de elaborar livros e manuais didáticos, a exemplo de Rudimentos de cálculo diferencial e de cálculo integral. São Paulo: Melhoramentos, 1939.

${ }^{29}$ Heloísa Alberto Torres (1895-1977), filha do jurista Alberto Torres, iniciou sua carreira no Museu Nacional como assistente de pesquisa de Edgard Roquette Pinto, sócio da Sociedade de Geografia. Em 1925, foi aprovada em primeiro lugar no concurso para professor substituto da área de Antropologia, Etnografia e Arqueologia do Museu Nacional. Dona Heloísa, como era conhecida, foi diretora daquela instituição, e colaborou com outras associações, tais como o Serviço do Patrimônio Histórico e Artístico Nacional e a Associação Brasileira de Antropologia. Cf. Mariza Corrêa, Antropólogas e antropologia. Belo Horizonte: Editora UFMG, 2003.

${ }^{30}$ Para Vidal La Blache, as paisagens naturais constituem superposições das ações humanas e dos dados naturais ao longo do tempo, portanto, uma herança histórica. Sobre a influência do tempo histórico do meio físico, ver: Roberto Lobato Corrêa, "As correntes do pensamento geográfico". In: Região e organização espacial. São Paulo: Ática, 1991; José William Vesentini, "Controvérsias geográficas: epistemologia e política" Confins, Revue Franco-brésilienne de Geographie, n. 2, 1 semestre, 2008. [En ligne], mis en ligne le 17 février 2008. URL : http://confins.revues.org/document1162.html. Consulté le 17 juillet 2008

${ }^{31}$ Delgado de Carvalho, op. cit., p. 100.

${ }^{32}$ Roberto Freire Seidl (1895-1948) foi professor de colégios e de liceus, baseou seu planejamento em obras clássicas e modernas, bem como realizou ampla pesquisa de gabinete nas repartições oficiais pertencentes a diversos ministérios e instituições, a exemplo da Inspetoria Federal de Portos, Rios e Canis do Ministério da Viação e Obras Públicas.

${ }^{33}$ Roberto Freire Seidl, Oceanografia (Formação e desenvolvimento). Rio de Janeiro, Est. Graphico Roland Rohe, 1929, p. vi.

${ }^{34}$ Idem, p. 36.

${ }^{35}$ SGRJ, "Relatório do Presidente da Sociedade general Moreira Guimarães relativo ao ano social de 1926". Revista da SGRJ, Rio de Janeiro, t.31, 1926-1927.

${ }^{36}$ Ver, Ruy Moreira. O Discurso do Avesso (para a crítica da geografia que se ensina). Rio de Janeiro: Dois Pontos, 1987, p. 32. Para este autor, a história da institucionalização do conhecimento geográfico e do seu ensino no Brasil corroborava com a valorização do Estado-Nação, o que se traduzia numa disciplina voltada para a ordem e para a valorização de seu território. Ver, também, José William Vesentini, Para uma geografia crítica da escola. São Paulo: Editora do autor, 2008, p. 11.

Artigo recebido em: 29/07/09

Aprovado para publicação em: 24/01/10 